\title{
In vitro Antioxidant, Thrombolytic and Cytotoxic Activities of Methanolic Leaf Extract and Its Fractionates of Erioglossum rubiginosum (Roxb.) Blume
}

\author{
Amirul Islam¹, S. M. Masud Rana ${ }^{1}$, Abhijit Das ${ }^{1}$, Monika Rani Saha ${ }^{2}$ \\ and Sultan Md. Gias Uddin ${ }^{3}$ \\ ${ }^{1}$ Department of Pharmacy, Noakhali Science and Technology University, Sonapur, Noakhali-3814, Bangladesh \\ ${ }^{2}$ Department of Pharmacy, Rajshahi University, Rajshahi-6205, Bangladesh \\ ${ }^{3}$ Department of Pharmacy, State University of Bangladesh, 77 Satmasjid Road, Dhanmondi \\ Dhaka-1205, Bangladesh
}

\begin{abstract}
The present study was carried out to investigate the methanolic extract of leaf of Erioglossum rubiginosum and its fractionates (petroleum ether, carbontetrachloride and chloroform fractions) for their in vitro antioxidant, thrombolytic and cytotoxic activities. Among the different fractions, the carbontetrachloride soluble fraction (CTF) showed significant antioxidant activity ( $\mathrm{IC}_{50}=30.32 \pm 0.08 \mu \mathrm{g} / \mathrm{ml}$ ) as compared to standard ascorbic acid $\left(\mathrm{IC}_{50}=5.87 \pm 0.21 \mu \mathrm{g} / \mathrm{ml}\right.$ ) and BHT ( $\mathrm{IC}_{50}=27.50 \pm 0.64 \mu \mathrm{g} / \mathrm{ml}$ ). The extract also inhibited $58.44 \pm 0.97 \%$ lipid from peroxidation and reveled excellent phenolic profile of about $128.56 \pm 1.02 \mathrm{mg}$ of GAE /g of extract. In the thrombolytic assay the highest \% of clot lysis was exhibited by the chloroform soluble fraction (CF) (28.57 $\pm 0.83 \%)$, while for streptokinase it was about $66.77 \pm 0.92 \%$. The $\mathrm{LC}_{50}$ values were found within the range of 12.92 to 80.06 $\mu \mathrm{g} / \mathrm{ml}$, while different solvent fractions were tested for cytotoxicity against brine shrimp nauplii. This is the first report of antioxidant, thrombolytic and cytotoxic activities of E. rubiginosum.
\end{abstract}

Key words: Erioglossum rubiginosum, DPPH, lipid peroxidation, total phenolic content, thrombolytic, brine shrimp lethality.

\section{INTRODUCTION}

Free radicals and other reactive oxygen species are constantly formed in the human body. Although oxygen is vital for aerobic forms of life, they can be toxic when generated in excess. As a result, reactive oxygen species (ROS) are recognized to be concerned in many cell disorders and in the development of many diseases including cardiovascular diseases, atherosclerosis, chronic inflammation etc. ${ }^{1}$ Synthetic antioxidants (such as ascorbic acid, butylated hydroxyanisole, butylated hydroxytoluene) are widely used but their use is being limited because of their toxic and carcinogenic effects. $^{2}$ Therefore, it is of great significance and necessity that research focuses on discovering

Correspondenceto: Monika Rani Saha

Email: saha_monika@yahoo.com

Tele: +88-0721-711110 (off), Fax: +88-0721-71114

Dhaka Univ. J. Pharm. Sci. 12(2): 153-158, 2013 (December) effective and nontoxic antioxidants from natural sources, to replace synthetic ones because of their probable carcinogenic activity which are harmful to the lungs and liver. ${ }^{3}$ Phenolic compounds from natural sources are well known for their metal chelating, reducing capability, hydrogen donating and most exceptionally capturing free radicals and stopping chain reactions. ${ }^{4}$ Inhibition of lipid peroxidation is gaining importance as oxidative damage caused by lipid peroxidation may be related to aging and disorders such as atherosclerosis, diabetes, cancer and other degenerative diseases. ${ }^{5}$ Thus, interest in finding natural antioxidants, without any unwanted effect has increased to a great extent.

Atherothrombotic diseases for example myocardial or cerebral infarction are severe consequences of the thrombus formed in blood vessels. ${ }^{6,7}$ Several drugs like tissue plasminogen activator, alteplase, anistreplase, urokinase, 
streptokinase (SK) etc. play an important role to dissolve blood clot in blood vessel. ${ }^{7}$ However, these drugs are sometimes responsible for some fatal disorders including hemorrhage, severe anaphylactic reaction and lacked specificity, etc. ${ }^{8}$ Therefore, efforts are underway to develop an attractive alternative and improved recombinant variants of these drugs. ${ }^{9}$

Since ancient times, drugs obtained from plant origin have always been a subject of interest to the scientists. The study of bioactive compounds from plant sources are of great importance because the general bioassay detects a wide spectrum of biological activities and a diversity of chemical structures of the particular plant. ${ }^{10}$

E. rubiginosum (local name- Bara Harina) is a shrub or small tree, with a compact, bushy crown and up to $12 \mathrm{~m}$ tall. It belongs to the family Sapindaceae and is available in forests at low and medium altitudes throughout the Philippines, northern India, Indo-China, Bangladesh, Thailand and also some other tropical countries. This plant is extensively used as folkloric medicine such as roots are used as astringent, leaves and fruits are used for the treatment of fever and poultice. ${ }^{11}$ As part of our continuing studies of medicinal plants of Bangladesh the methanolic extract and the different fractions of $E$. rubiginosum leaf extract growing in Bangladesh were screened for antioxidant, thrombolytic and cytotoxic activities for the first time and we, here in, report the results of our preliminary investigation.

\section{MATERIALS AND METHODS}

Chemicals and reagents. Lyophilized S-Kinase ${ }^{\mathrm{TM}}$ (Streptokinase) vial (1,500,000 I.U.) was purchased from Popular Pharmaceutical Ltd., Bangladesh. DPPH (1, 1-diphenyl-2-picryl hydrazyl), acetic acid and gallic acid were obtained from Sigma Chemical Co. USA. Ascorbic acid was obtained from SD Fine chem. Ltd. India. Methanol, Folin-Ciocalteu reagent, sodium carbonate and dimethyl sulfoxide (DMSO) were purchased from Merck, Darmstadt, Germany. All chemicals used were of analytical grade.
Collection and preparation of plant material. The leaves of E. rubiginosum were collected from Dhaka, Bangladesh, in July 2012. The plant was identified by the taxonomist of Bangladesh National Herbarium, Mirpur, Dhaka, Bangladesh and a voucher specimen has been deposited in the herbarium unit (Accession no DACB 38566). The sun dried powdered leaves $(500 \mathrm{mg})$ of $E$. rubiginosum was macerated in $2.5 \mathrm{~L}$ of $99.8 \%$ methanol. After 15 days the solution was filtered using filter cloth and Whatman ${ }^{\circledR}$ filter paper No. 1 . The resulting filtrates were then evaporated in a rotary evaporator at $40{ }^{\circ} \mathrm{C}$ and a blackish-green semisolid mass (110g) of the extract was obtained. A portion of the concentrated methanolic extract was partitioned by modified Kupchan method ${ }^{12}$ and the resulting partitionates were pet-ether (PEF), carbontetrachloride (CTF) and chloroform (CF) fractions were used for assays of various biological activities.

\section{Antioxidant activity}

DPPH free radical scavenging activity. The ability of methanolic extracts and different fractions of E. rubiginosum to scavenge 1, 1-diphenyl-2picryl-hydrazyl (DPPH) free radicals was estimated by the reported methods. ${ }^{13,14}$ Butylated hydroxytoluene (BHT) and ascorbic acid were used as reference standards. The DPPH solution without sample solution was used as control and 95\% methanol was used as blank.

The percentage of radical scavenging activity was calculated by the following equation:

Radical scavenging $(\%)=\left[\left(\mathrm{A}_{0}-\mathrm{A}_{1} / \mathrm{A}_{0}\right) \times 100\right]$

Where, $\mathrm{A}_{0}=$ Absorbance of the control and $\mathrm{A}_{1}=$ Absorbance of the sample extracts.

Lower absorbance values show higher free radical scavenging activity. The 50\% inhibitory concentration value $\left(\mathrm{IC}_{50}\right)$ was indicated as the effective concentration of the sample that was required to scavenge $50 \%$ of the DPPH free radicals.

Inhibition of lipid peroxidation. A modified thiobarbituric acid reactive species (TBARS) assay was used to measure the lipid peroxide formed using egg yolk homogenates as lipid-rich media, as 
described by Dissanayake et $a .^{5}$ with minor modification. Briefly, $0.5 \mathrm{ml}$ of egg yolk homogenate $(10 \% \mathrm{v} / \mathrm{v})$ was added to $0.1 \mathrm{ml}$ of the extracts (concentration $10 \mu \mathrm{g} / \mathrm{ml}$ ). The volume was then made up to $1.0 \mathrm{ml}$ with distilled water. Then, $1.5 \mathrm{ml}$ of acetic acid was added, followed by $1.5 \mathrm{ml}$ of thiobarbituric acid (TBA) in SDS solution (Sodium dodecyl sulfate). The resulting mixture was vortex mixed and heated at $95^{\circ} \mathrm{C}$ for 1 hour. After cooling, 5 $\mathrm{ml}$ of butanol was added and the mixture was centrifuged at $3000 \mathrm{rpm}$ for $10 \mathrm{~min}$. The same process was repeated for standard ascorbic acid and butylated hydroxytoluene (BHT). The absorbance of the upper organic layer was measured at $532 \mathrm{~nm}$ and the percentage inhibition was calculated with the formula:

$\%$ Inhibition of lipid peroxidation $=\left(1-\mathrm{A}_{1} / \mathrm{A}_{2}\right) \times 100$ Where, $A_{1}=$ Absorbance of test sample and $A_{2}=$ Absorbance of fully oxidized control.

Determination of total phenolic contents. Total phenolic contents were determined by the Folinciocalteu method ${ }^{15}$ using gallic acid as standard. The phenolic contents of all samples were expressed as mg of GAE (gallic acid equivalent)/g of the extracts.

Thrombolytic activity. For this $7 \mathrm{ml}$ blood was drawn from healthy Bangladeshi human volunteers ( $n$ $=5$ ) (aged 20-23 years) who did not have a history of oral contraceptive or anticoagulant therapy. Blood (500 $\mu \mathrm{l}$ ) was transferred to each of the 7 previously weighed sterilized micro-centrifuge tubes and allowed them to form clots. $5 \mathrm{ml} 0.9 \%$ sodium chloride $(\mathrm{NaCl})$ was added to the commercially available lyophilized S-Kinase ${ }^{\mathrm{TM}}$ (Streptokinase) vial of 15, 00,000 I.U. and mixed properly. This solution was used as a stock from which $100 \mu \mathrm{l}$ (30,000 I.U) was used for in vitro thrombolytic assay ${ }^{7}$ using streptokinase (SK) as positive control. As a positive control, $100 \mu \mathrm{l}$ of streptokinase (SK) and as a negative non-thrombolytic control, $100 \mu \mathrm{l}$ of distilled water were separately added to the control tubes. All tubes were then incubated at $37^{\circ} \mathrm{C}$ for 90 minutes and observed for clot lysis. After incubation, the released fluid was removed and tubes were again weighed to observe the difference in weight after clot disruption.
The differences in weights taken before and after clot lysis were expressed as percentage of clot lysis as shown below:

$\%$ of clot lysis $=($ wt of released clot $/$ clot wt $) \times 100$

Cytotoxic activity. The cytotoxicity assay was conducted using brine shrimp lethality test according to the method described by Meyer et al. ${ }^{16}$ Then ten brine shrimp matured shrimps were applied to each of all experimental vials and control vial. The mortality of brine shrimp was observed after 24 hours of treatment for each of the concentrations. An approximate linear correlation was observed, when logarithm of concentration versus percentage of mortality was plotted and the values of $\mathrm{LC}_{50}$ were calculated by probit analysis using SPSS (version 16). Vincristine sulphate was used as positive control.

Statistical analysis. Data were processed and analyzed using SPSS (version 16.0, IBM Corporation, NY, USA).The results of antioxidant and thrombolytic activity were expressed as mean \pm standard deviation (SD) using One-way analysis of variance (ANOVA) followed by Dunnet's $t$-test where $P<0.05$ was considered as statistically significant. For cytotoxic test, the median lethal concentration(s) $\left(\mathrm{LC}_{50}\right)$ of the test samples were calculated using probit analysis method described by Finney. ${ }^{17}$

\section{RESULTS AND DISCUSSION}

The results of the free radical scavenging activity of the methanolic extract of leaves of E. rubiginosum and its different fractions are presented in the Table 1 and these results are compared to that of ascorbic acid and BHT. The results demonstrated that the 50\% inhibitory concentration $\left(\mathrm{IC}_{50}\right)$ of E. rubiginosum leaves extracts were within the range of 30 to $155 \mu \mathrm{g} / \mathrm{ml}$. Among different fractions the carbon tetrachloride fraction (CTF) showed highest free radical scavenging activity with lowest $\mathrm{IC}_{50}$ value (30.32 $\pm 0.08 \mu \mathrm{g} / \mathrm{ml}$ ), while the standard sample ascorbic acid and BHT showed $\mathrm{IC}_{50}$ values of $5.87 \pm 0.21$ and $27.50 \pm 0.64 \mu \mathrm{g} / \mathrm{ml}$, respectively. In our present study it was found that the carbontetrachloride fraction (CTF) of E. rubiginosum leaves 
extract showed better free radical scavenging activity than the others.

The inhibition of lipid peroxidation by the methanolic extract and its different fractionates of $E$. rubiginosum leaves are given in Table 1 . From the table, it is evident that the positive control ascorbic acid and BHT showed $5.87 \%$ and $27.50 \%$ lipid peroxidation inhibition activity, respectively. Among the different fractions the highest lipid peroxidation

Table 1. Antioxidant activity of crude methanolic extracts and their solvent fractions of $E$. rubiginosum leaves.

\begin{tabular}{cccc}
\hline Extract/Fraction & $\mathrm{IC}_{50}(\mu \mathrm{g} / \mathrm{ml})$ & \% of Inhibition & $\begin{array}{c}\text { Total phenol content (mg of GAE /g of } \\
\text { extractive) }\end{array}$ \\
\hline ME & $60.50 \pm 0.30^{\mathrm{a}^{* * * *}}$ & $24.94 \pm 0.52$ \\
CTF & $30.32 \pm 0.08^{\mathrm{b}^{* * *}}$ & $41.52 \pm 1.32^{\mathrm{a}^{* * * *}}$ & $128.56 \pm 1.02$ \\
CF & $94.73 \pm 0.70^{\mathrm{a}^{* * *}}$ & $58.44 \pm 0.97^{\mathrm{b***}}$ & $20.81 \pm 0.39$ \\
PEF & $155.41 \pm 0.62^{\mathrm{a}^{* * *}}$ & $32.47 \pm 1.13^{\mathrm{a}^{* * * *}}$ & $10.94 \pm 0.23$ \\
Ascorbic Acid & $5.87 \pm 0.21$ & $14.28 \pm 0.46^{\mathrm{a}^{* * *}}$ & - \\
BHT & $27.50 \pm 0.64$ & $80.52 \pm 0.59$ & - \\
\hline
\end{tabular}

Values are expressed as the mean of triplicate measurements \pm standard deviation (SD). Significant at ${ }^{* * *} p<0.001$ compared to ascorbic acid. Significant at ${ }^{\mathrm{a}} p<0.001$ and ${ }^{\mathrm{b}} p<0.01$ compared to BHT. ME $=$ Methanolic extract, PEF= Petroleum ether fraction, CTF= Carbon tetrachloride fraction, $\mathrm{CF}=$ Chloroform fraction.

inhibitory activity was showed by carbon tetrachloride fraction (CTF) (58.44 $\pm 0.97 \%)$, while the petroleum ether fraction (PEF) showed lowest inhibitory activity (14.28 \pm 0.46$)$. Meanwhile, this difference in the level of antioxidant activity of different fractions may be due to the presence of different types and concentration of antioxidants. ${ }^{18}$ Based on the results it may be said that the leaves of E. rubiginosum protects against lipid peroxidation.

The methanolic extract of E. rubiginosum leaves and its different fractions were shown to contain a good amount of phenolic compounds. Total phenolic compounds were reported as gallic acid equivalents by reference to a standard curve $(y=0.002 x+0.107$; $\left.\mathrm{R}^{2}=0.889\right)$. From the test results it can be seen that the carbon tetrachloride fraction (CTF) contained the higher amount of phenolic compounds (128.56 \pm 1.02 mg of GAE/g), which supports its good free radical scavenging and lipid peroxidation inhibitory action. On the other hand, the petroleum ether fraction (PEF) was shown to contain lowest amount of phenolic compounds (10.94 $\pm 0.23 \mathrm{mg}$ of GAE/g). The reason behind this may be that the solvent polarity plays a key role in increasing solubility of phenolic compounds. $^{19}$

Statistical representation of the effective clot lysis percentage by different fractions of the plant $E$. rubiginosum leaves extract, positive thrombolytic control (Streptokinase) and negative control (water) is represented in Table 2. The results demonstrated that the different fraction of plant leaves extract showed moderate clot lysis activity (ranging from

Table 2. Effect of methanolic extract and different partitionates of $E$. rubiginosum leaves and the controls on in vitro clot lysis.

\begin{tabular}{lc}
\hline Extract/Fraction & \% of Clot lysis \\
\hline ME & $27.41 \pm 0.26^{* * *}$ \\
PEF & $21.36 \pm 0.47^{* * *}$ \\
CTF & $27.57 \pm 0.60^{* * *}$ \\
CF & $28.57 \pm 0.83^{* * *}$ \\
Streptokinase (standard) & $66.77 \pm 0.92$ \\
Distilled water (Negative control) & $2.57 \pm 0.19$ \\
\hline
\end{tabular}

Statistical representation of percent clot lysis by different treatments, and negative control (sterile distilled water) done by Dunnet's $t$-test analysis; clot lysis \% is represented as mean \pm S.D. Significant at ${ }^{* * *} p<0.001$ compared to streptokinase.

$18.10 \%$ to $28.57 \%$ ) as compared to standard streptokinase's (30,000 I.U.) clot lysis (66.77\%) activity (Figure 1). Among different fractions the highest clot lysis activity was demonstrated by the chloroform fraction (CF) (28.57 $\pm 0.83 \%)$. It was also seen from the results that the mean difference in clot lysis percentage between positive and negative control was very significant $(p<0.001)$. The result of the \% clot disruption of the chloroform fraction (CF) of the E. rubiginosum leaves extract revealed that the 
plant extract may be a good candidate for further study for thrombolytic activity.

The results of brine shrimp lethality assay are presented in Table 3 . The $\mathrm{LC}_{50}$ indicated the concentration by which $50 \%$ of the shrimps were killed. The effects produced by the methanolic extract and its fractionates were compared to that of the positive control vincristine sulphate (VS) and significant $(P<0.001)$ results were found. The carbon tetrachloride fraction (CTF) demonstrated highest cytotoxic potential with least $\mathrm{LC}_{50}$ value $(12.92 \pm 0.71$ $\mu \mathrm{g} / \mathrm{ml})$. The positive control vincristine sulphate showed the $\mathrm{LC}_{50}$ value of $0.451 \pm 0.03 \mu \mathrm{g} / \mathrm{ml}$. In our present study the cytotoxic assay was performed using brine shrimp lethality bioassay and the highest cytotoxic activity of E. rubiginosum leaves extract was found in carbon tetrachloride fraction (CTF). So, it may be predicted that the bioactive compounds present in the E. rubiginosum leaves extract may be accountable for the possible cytotoxic effect of this plant.

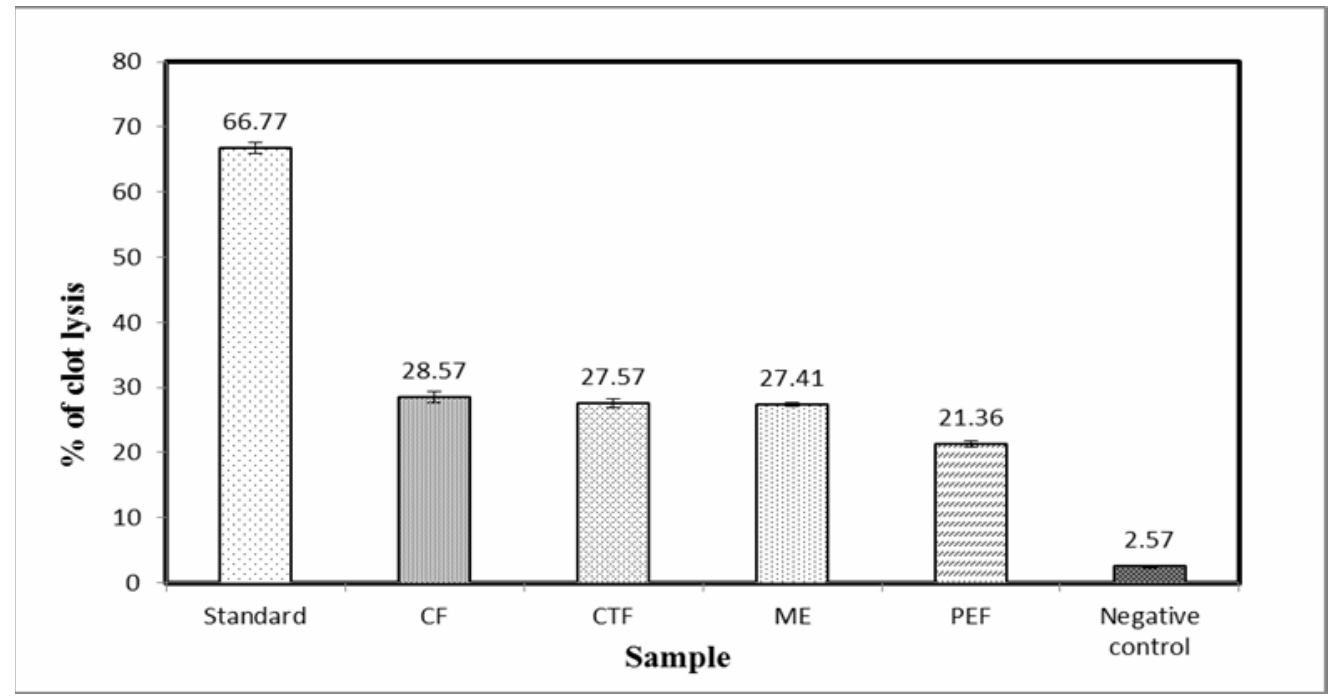

Figure 1. Plot of \% of clot lysis versus sample of crude methanolic extract, the petroleum ether, carbon tetrachloride, chloroform fractions, negative control and standard (Streptokinase) of E. rubiginosum leaves. ME: Methanolic extract, PEF: Pet-ether fraction, CTF: Carbon tetrachloride fraction, CF: Chloroform fraction.

Table 3. LC $_{50}$ values of of $E$. rubiginosum extractives in brine shrimp lethality bioassay.

\begin{tabular}{lc}
\hline Extract/Fraction & $\mathrm{LC}_{50}(\mu \mathrm{g} / \mathrm{ml})$ \\
\hline $\mathrm{ME}$ & $29.47 \pm 0.64^{* * *}$ \\
$\mathrm{PEF}$ & $80.06 \pm 0.15^{* * *}$ \\
$\mathrm{CTF}$ & $12.92 \pm 0.71^{* * *}$ \\
$\mathrm{CF}$ & $29.01 \pm 0.40^{* * *}$ \\
Vincristine Sulphate & $0.451 \pm 0.03$ \\
\hline
\end{tabular}

Data of $\mathrm{LC}_{50}$ represents mean \pm standard deviation (SD) of triplicate analysis. Significant at ${ }^{* * * *} p<0.001$ compared to Vincristine sulphate.

Since the plant has a lot of biological activities, future studies will be focused on the isolation of biologically active compounds.

\section{ACKNOWLEDGEMENTS}

The Authors would like to acknowledge the Chairman, Department of Pharmacy, Noakhali Science and Technology University, Noakhali for providing support to conduct the project work. The authors are also thankful to the Director, Poultry Research and Training Center, Chittagong Veterinary and Animal Science, Chittagong-4202, Bangladesh for providing lab facilities.

\section{REFERENCES}

1. Aruoma, O.I., Kaur, H. and Halliwell, B. 1991.Oxygen free radicals and human diseases. J. Royal Soc. Health. 111, 172177.

2. Rahman, M.A. and Islam MS. 2013. Antioxidant, antibacterial and cytotoxic effects of the phytochemicals of whole Leucas aspera extract. Asian Pac. J. Trop. Biomed. 3, 273-279. 
3. Branen, A.L. 1975.Toxicology and biochemistry of butylated hydroxyanisole and butylated hydroxytoluene. J. Am. Oil Chem. Soc. 52, 59-63.

4. Cook, N.C. and Samman S. 1996. Flavonoids: Chemistry, metabolism, cardioprotective effects, and dietary sources, Nutr. Biochem. 7, 66-76.

5. Dissanayake, D.P., Abeytunga, D., Vasudewa, N.S. and Ratnasooriya, W.D. 2009. Inhibition of lipid peroxidation by extracts of Pleurotus ostreatus. Pharmacog. Mag. 5, 266271.

6. Davies, M.J. and Thomas, A.C. 1985. Plaque fissuring: the cause of acute myocardial infarction, sudden ischaemic death and crescendo angina. Br. Heart J. 53, 363-373.

7. Prasad, S., Kashyap, R.S., Deopujari, J.Y., Purohit, H.J., Taori, G.M. and Daginawala, H.F. 2007. Effect of Fagonia arabica (Dhamasa) on in vitro thrombolysis. BMC Comple. Alternative Med. 7, 36.

8. Rouf, SA, Moo-Young M, Chisti Y. 1996. Tissue-type plasminogen activator: characteristics, applications and production technology. Biotechnol. Adv. 14, 239-266.

9. Dewan, S.M.R. and Das, A. 2013. Investigation of in vitro thrombolytic potential and phytochemical nature of Crinum latifolium L. leaves growing in coastal region of Bangladesh. Int. J. Biol. Pharma. Res. 4, 1-7.

10. Montanher, A.B.P. and Pizzolatti, M.G. 2002. An application of the brine shrimp bioassay for general screening of Brazilian medicinal plants. Acta Farm. Bonaerense. 21, 175178.

11. Stuartxchange.com[Internet].[Updated 2011 November; Cited 2013 May 11]. Available from: http://www.stuart xchange.com/Kalayo.html
12. Van Wagenen, B.C., Larsen, R., Cardellina, J.H., Ran dazzo, D., Lidert, Z.C. and Swithenbank, C. 1993. Ulosantoin, a potent insecticide from the sponge Ulosa ruetzleri. J. Org. Chem. 58, 335-337.

13. Das, M., Sarma, B.P., Ahmed, G., Nirmala, C.B. and Choudhury, M.K. 2012. In vitro antioxidant activity and total phenolic content of Dillenia indica and Garcinia penducalata, commonly used fruits in Assamese cuisine. Free Rad. Antiox. 2, 30-36.

14. Islam, M.R., Parvin, M.S., Islam and M.E .2012.Antioxidant and hepatoprotective activity of an ethanol extract of Syzygium jambos (L.) leaves. Drug Discoveries \& Therapeutics. 6, 205-211.

15. Khatoon, M., Islam, E., Islam, R., Rahman, A.A., Alam, AHM K., Khondkar, P., Rashid, M. and Parvin, S. 2013. Estimation of total phenol and in vitro antioxidant activity of Albizia procera leaves. BMC Research Notes 6, 121

16. Meyer, B.N., Ferrigni, N.R., Putnam, J.E., Jacobsen, L.B., Nichols, D.E. and McLaughlin, J.L. 1982. Brine shrimp: a convenient general bioassay for active plant constituents. Planta. Med. 45, 31-34.

17. Finney, D.J. 1971. Probit analysis, $3^{\text {rd }}$ ed. Cambridge University Press, Cambridge.

18. Rezaeizadeh, A., Zakaria, Z.B.A.B., Abdollahi, M., Meng, G.Y., Mustapha, N.M., Hamid, M.B. and Ibrahim, T.A.B.T. 2011. Antioxidant and antihyperglycaemic effects of an aqueous extract from Momordica charantia fruit in a type II diabetic rat model. J. Med. Plants. Res. 5, 2990-3001.

19. Naczk, M. and Shahidi, F. 2006. Phenolic in cereals, fruit and vegetables: occurrence, extraction and analysis. J. Pharm. Biomed. Anal. 41, 1523-1542. 